\title{
Integrating local agriculture into nutrition programs can benefit children's health
}

\author{
by Rachel E. Scherr, Rachel J. Cox, Gail Feenstra \\ and Sheri Zidenberg-Cherr
}

Childhood obesity has multiple interrelated causes and so should be addressed with multiple interventions, including innovative nutrition education programs that encourage healthy lifestyle choices in children. Research indicates that garden-based nutrition education increases fruit and vegetable preferences and consumption in children. Additionally, many reports on Farm to School programs indicate they promote both increased consumption of fruits and vegetables and participation in the National School Lunch Program. Within California, UC Agriculture and Natural Resources plays a leadership role in school garden and Farm to School programs. We provide a relevant literature review and assess the role of UC Cooperative Extension (UCCE) in program implementation and assessment, including results from a survey of UCCE advisors and directors. All respondents reported implementation of garden-based nutrition education and Farm to School programs; however, evaluation occurred much less frequently.

\footnotetext{
$\neg \neg$ he epidemic of childhood obesity in the United States is a leading public health concern. Recent estimates indicate that $31.7 \%$ of children aged 2 to 19 years are overweight (at or above the 85th percentile for body-mass-index-for-age) and $16.9 \%$ are obese (at or above the 95th percentile) (Ogden et al. 2010). The issue of obesity is complex, with numerous interrelated causes. It stands to reason that any problem with this degree of complexity cannot be solved through programs that address a single contributing factor. Multiple government agencies have echoed this logic in a call for integrative and innovative strategies that demonstrate
}

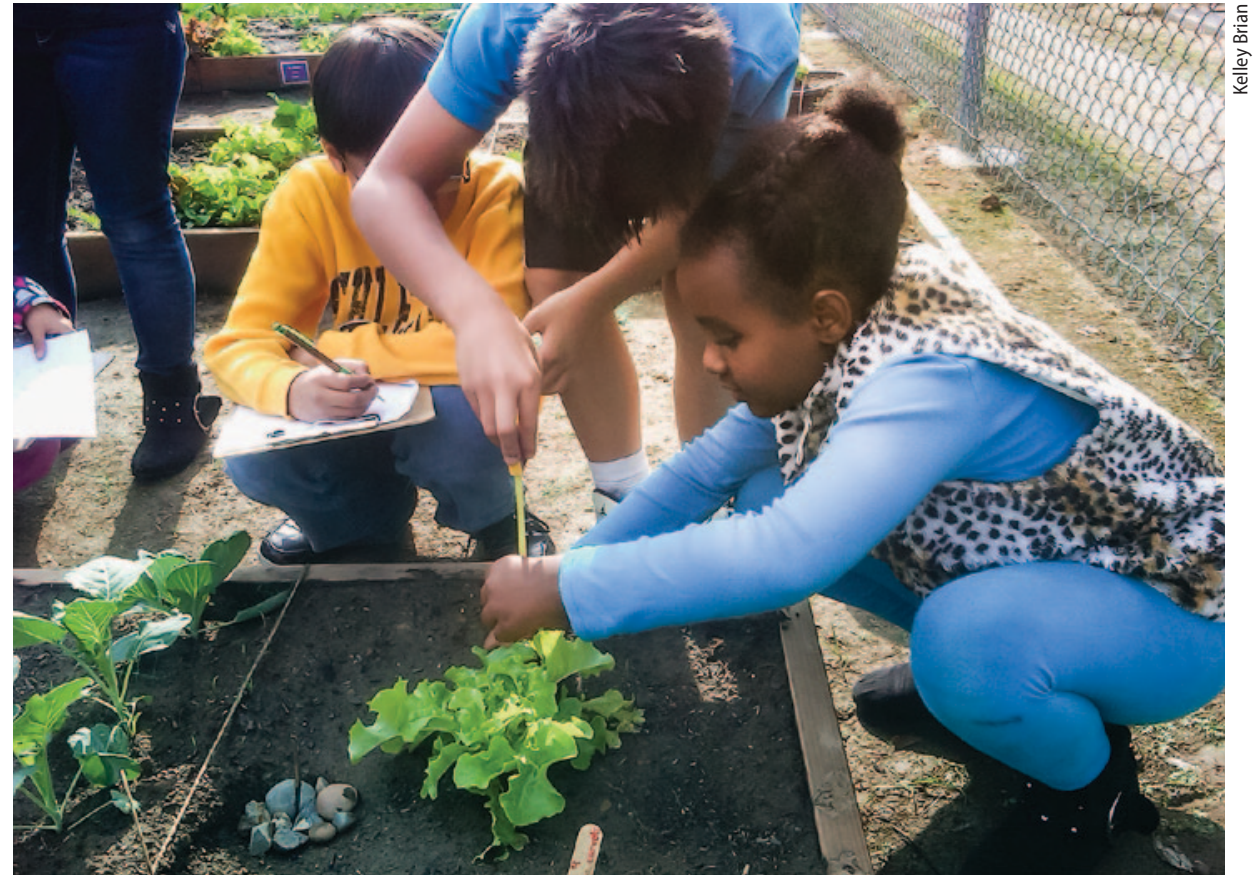

Having established a school garden, students at a Northern California elementary school take measurements of plant growth as a part of their science curriculum. It has been repeatedly shown that garden-enhanced nutrition education has a positive effect on children's fruit and vegetable choices and intake.

promise in promoting healthy lifestyle choices among children.

These strategies include implementation at multiple levels, from individual to family to community to society (CAPOP 2012). The need for healthier school environments, improved dietary and physical activity behaviors at home and community engagement in efforts to improve the health and well-being of our nation's children was emphasized in a recent joint initiative released by first lady Michelle Obama, the surgeon general and the Department of Health and Human Services (US DHHS 2010). To help reach these goals, President Obama issued a memorandum on Feb. 9, 2010, calling for the establishment of a federal task force on childhood obesity (WHTF 2010).

In an Institute of Medicine (National Academy of Sciences) report, key stakeholders were urged to commit to childhood obesity prevention and to strive not only to develop innovative programs but to monitor the progress and evaluate the efficacy of new and existing obesity prevention policies and programs and work to disseminate promising practices for maximum impact (CPPCO 2007). The committee cited nutrition education and gardening as examples of promising, innovative practices to increase fruit and vegetable consumption through both Farm to School programs and school gardens. Other organizations, including the Centers for Disease Control and Prevention, encouraged creating a school environment that supports regular physical activity and healthy eating habits (Action for Healthy Kids 2008; CDC 1996, 2003).

Conceptual frameworks are key to the development, implementation and evaluation of successful health programs, as they can provide a system for linking and evaluating the multiple components that influence health behavior (Story et al. 2008). Effective, sustainable programs targeting obesity prevention for the individual are needed within the context of the socio-ecological model, which succinctly

Online: http://californiaagriculture.ucanr.edu/ landingpage.cfm?article=ca.v067n01p30\&fulltext=yes DOI: 10.3733/ca.v067n01p30 
describes the relationship of choices made by an individual to the other spheres of influence within the environment and society. These spheres of influence are multifaceted and include factors such as income, ethnicity and cultural values and settings such as schools and retail food establishments. Consequently, measurable progress in reducing childhood obesity requires a multifaceted approach: a coordinated, comprehensive program that integrates messages regarding nutrition, physical activity and health with a child's immediate environment and surrounding community (CPPCO 2007). Adequate access to healthy food and physical recreation opportunities is essential to promote sustained behavior changes (Briggs et al. 2010).

Schools and after-school programs provide a unique setting for this approach, as they provide access to children, parents, families, educators, administrators and community members (Economos et al. 2007). The purpose of this article is to examine garden-enhanced nutrition education and Farm to School programs. Further, a questionnaire was developed and distributed to UC Cooperative Extension (UCCE) advisors and directors to assess their role in garden-enhanced nutrition education and Farm to School programs. Results from this questionnaire highlight UCCE's integral role in this field.

\section{Garden-enhanced education}

School gardens were first implemented in the United States at the George Putnam School in Roxbury, Massachusetts, in 1890, and by 1918 there was at least one in every state (Kohlstedt 2008). During World Wars I and II, more than a million children were contributing to U.S. food production with victory gardens, which were part of the U.S. School Garden Army Program (Hayden-Smith 2006; Subramaniam 2002). More recently, incorporating gardens into the educational environment has become more popular worldwide, due partly to the appreciation of the importance of environmental awareness and integrated learning approaches to education (Kane and HaydenSmith 2008).

As the agricultural powerhouse of the nation (California Economy 2011), California is poised to serve as a model for agriculture-enhanced nutrition and health education. Within California, the impetus to establish gardens in every school gained momentum in 1995, when then-State Superintendent of Public Instruction Delaine Eastin launched an initiative to establish school gardens as learning laboratories or outdoor classrooms (Hazzard et al. 2011). Assembly

\section{Providing children with options to make healthy choices rather than imposing restrictions has long-term positive effects on weight.}

Bill (AB) 1535 created the California Instructional School Garden Program, allowing the California Department of Education to allocate \$15 million for grants to promote, develop and sustain instructional school gardens. About 40\% of California schools applied for these grants, and \$10.9 million was awarded (Hazzard et al. 2012).

It has been repeatedly shown that garden-enhanced nutrition education has a positive effect on children's fruit and vegetable preferences and intakes (Graham et al. 2005; Morris et al. 2001). For example, after a 17-week standards-based, garden-enhanced nutrition education program, fourth-grade students preferred a trol students. The program included nine greater variety of vegetables than did conwith garden activities. For example, students learned that plants and people need similar nutrients. Many of these improvements persisted and were maintained at a 6-month follow-up assessment (Morris and Zidenberg-Cherr 2002). In a similar study of a 12-week program combining in-class nutrition lessons coordinated

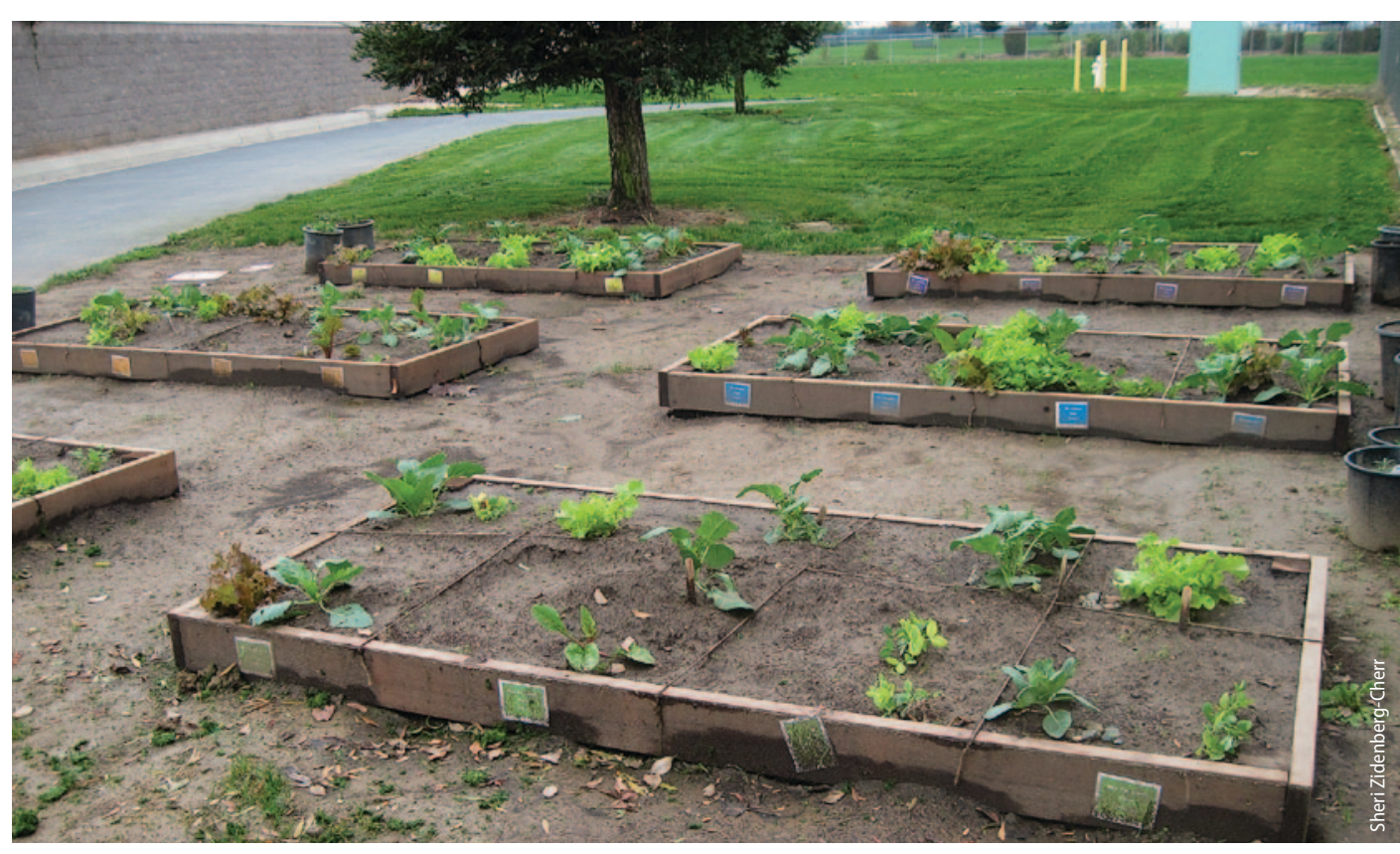

Researchers in the Shaping Healthy Choices Program have established cool-weather crops in this Northern California school garden. The program will be sustainable with existing infrastructure, addressing barriers such as time constraints, lack of funding and lack of teacher interest. nutrition lessons with horticulture, sixthgrade students likewise improved their vegetable preferences and consumption (McAleese and Rankin 2007). In addition, after a 13-week garden-enhanced nutrition program, middle school children ate a greater variety of vegetables than they had initially (Ratliffe et al. 2011).

While garden-enhanced nutrition education is one innovative method to improve children's vegetable preferences and intake, researchers and educators consistently call for multicomponent interventions to have the greatest impact on student health outcomes. Suggested additional components include classroom education, Farm to School programs, healthy foods available on campus, family involvement, school wellness policies 
and community input (Briggs et al. 2010; Ozer 2007; Robinson-O'Brien et al. 2009). Moreover, the literature indicates that providing children with options to make healthy choices rather than imposing restrictions has long-term positive effects on weight (Gubbels et al. 2011). Taken together, it is reasonable to suggest that we are most likely to achieve long-lasting beneficial changes by coordinating a comprehensive garden-enhanced nutrition education program with school wellness policies, offering healthy foods on the school campus, fostering family and community partnerships and incorporating regional agriculture.

\section{Farm to School programs}

Farm to School programs connect $\mathrm{K}-12$ schools and regional farms, serving healthy, local foods in school cafeterias or classrooms. General goals include improving student nutrition; providing agricultural, health and nutrition education opportunities; and supporting small and mid-sized local and regional farms (National Farm to School Network 2012). Born through a small group of pilot projects in California and Florida in the late 1990 s, Farm to School is now offered in all 50 states, with more than 2,000 programs nationwide in 2010 (National Farm to School Network 2012). The dramatic increase in the number and visibility of Farm to School programs can likely be attributed to factors including heightened public awareness of childhood obesity, expanding access to local and regional foods in school meals, concerns about environmental and agricultural issues as well as the sustainability of the U.S. food system.

Farm to School programs provide a unique opportunity to address both nutritional quality and food system concerns. From a nutrition and public health standpoint, these programs improve the nutritional quality of meals served to a large and diverse population of children across the country. From a food systems and economic perspective, Farm to School programs connect small and mid-sized farms to the large, stable and reliable markets created by the National School Lunch Program (Allen and Guthman 2006). Farm to School programs require partnerships that include a state or community organization, a local farmer or agricultural organization, a school nutrition services director and parents. Historically, Farm

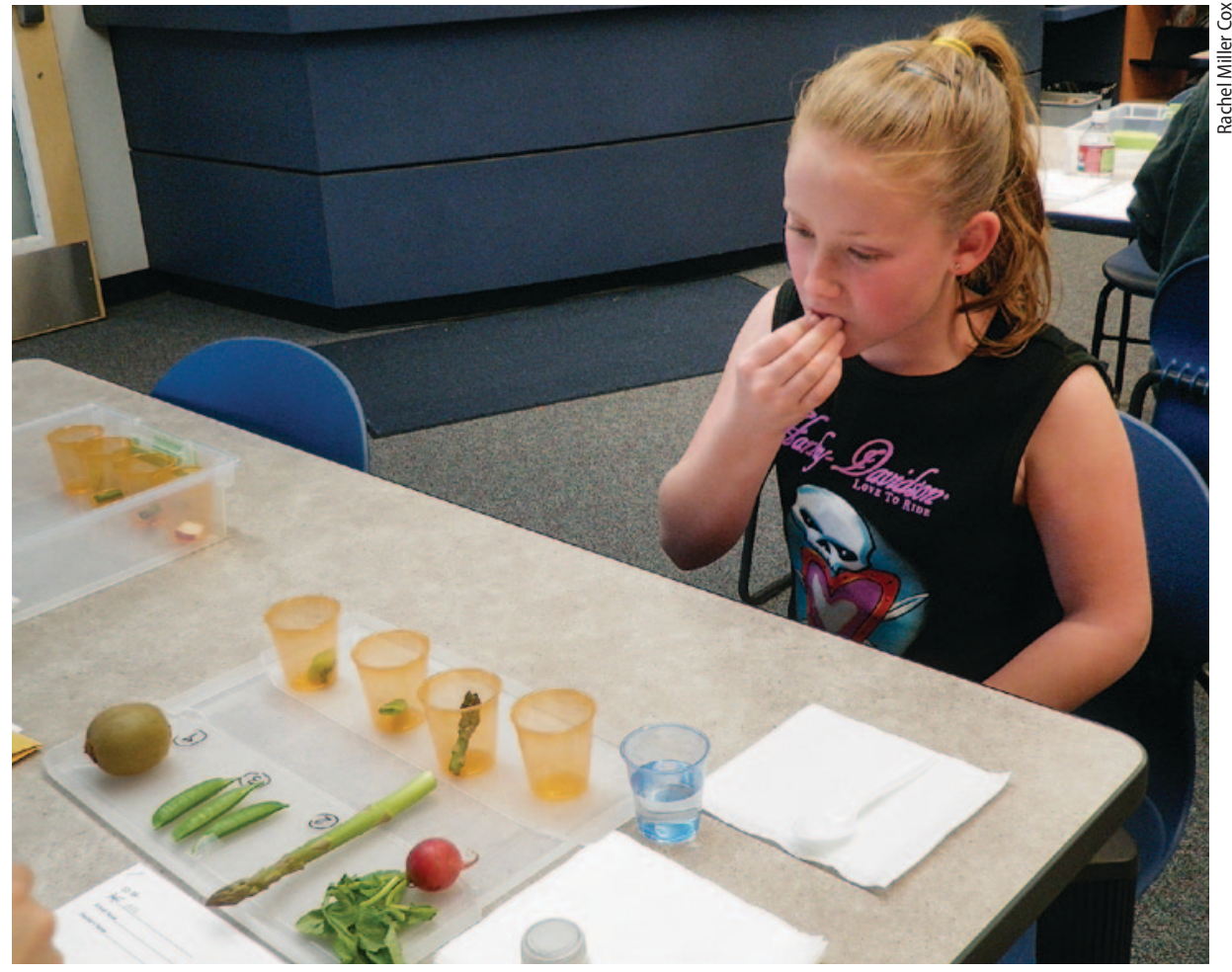

A fourth-grade student in a Northern California school district participates in a vegetable preference taste-test survey, part of a project funded by the California Department of Food and Agriculture Speciality Crops program. Farm to School programs improve nutritional quality of meals served to children, and connect small and mid-sized farms to large, stable and reliable markets.

to School programs are driven, supported and defined by a community. Because they reflect the diverse and unique communities they serve, individual Farm to School programs also vary from location to location, in addition to sharing the characteristics described above.

The first national Farm to School programs were initiated in 2000 and soon gained momentum in California, with support from the USDA Initiative for Future Agriculture and Food Systems as well as the W.K. Kellogg Foundation. In 2005, Senate Bill 281 established the California Fresh Start Program to encourage and support additional portions of fresh fruits and vegetables in the School Breakfast Program. This bill also provided the California Department of Education with $\$ 400,000$ for competitive grants to facilitate developing the California Fresh Start Program (National Farm to School Network 2012). Concomitant with the growth of Farm to School programs, the National Farm to School Network was formed in 2007 with input from over 30 organizations and today engages food service, agricultural and community leaders in all 50 states. The evolution of this network has influenced school food procurement and nutrition/ food education nationwide (Feenstra and Ohmart 2012).

\section{Farm to School impact}

Evaluations of Farm to School impact have been conducted since the program's inception. A 2008 review of 15 Farm to School evaluation studies, which were conducted between 2003 and 2007, showed that 11 specifically assessed Farm to School-related dietary behavior changes (Joshi et al. 2008). Of these 11 studies, 10 corroborated the hypothesis that increased exposure to fresh Farm to School produce results in positive dietary behavior changes. In addition, a 2004-2005 evaluation of plate waste at the Davis Joint Unified School District salad bar showed that $85 \%$ of students took produce from the salad bar and that $49 \%$ of all selected salad bar produce was consumed (Feenstra and Ohmart 2004, 2005). Additionally, school record data demonstrates that throughout the 5 years of the 2000-to-2005 Farm to School program, overall participation in the school lunch program ranged from a low of $23 \%$ of enrollment to a high of $41 \%$, with an overall average of $32.4 \%$. This compared to 
$26 \%$ participation before salad bars were introduced. Overall participation in the hot lunches averaged $27 \%$ of enrollment (Feenstra and Ohmart 2005).

While Farm to School evaluations generally indicate positive outcomes (Joshi and Azuma 2009; Joshi et al. 2008), conclusive statements regarding the overall impact of such programs on dietary behavior cannot be made. This can be attributed to the substantial variation in Farm to School structure from district to district, and variation in the study design and methodologies of early program evaluations. Methods for evaluating dietary impact outcomes most commonly include using National School Lunch Program participation rates and food production data as proxies for measuring consumption. Additional evaluation methods include using self-reported measures of consumption such as parent and student food recalls or frequency questionnaires, and direct measures of consumption such as school lunch tray photography and plate waste evaluation.

There are relatively few studies using an experimental design to evaluate the impact of Farm to School programs on fruit and vegetable intake, and even fewer of these studies use controls. Moreover, the Farm to School evaluation literature has no peer-reviewed dietary behavior studies using a randomized, controlled experimental design, which is undoubtedly due to the complex challenges inherent in community research. For example, schools may view the demands of research (such as allowing evaluations of program outcomes) as burdensome or may question the benefits of serving as control sites.

\section{UC ANR's role}

Due partly to its year-round growing season, California has more Farm to School programs than most, if not all, states. UC Davis pioneered some of the early uncontrolled studies quantifying Farm to School procurement, costs and consumption. UC ANR is now conducting new controlled studies to collect more rigorous data, which will differentiate outcomes of Farm to School programs from those due to other environmental factors.

To clarify the role(s) of UC ANR in garden-based nutrition education and Farm to School programs, a questionnaire was developed and administered through
Survey Monkey in November 2011. This survey was sent to 60 UCCE academic personnel, including county directors; Nutrition, Family and Consumer Sciences (NFCS) advisors; 4-H Youth Development (4-HYD) advisors; and others. For the purposes of this questionnaire, Farm to School was broadly defined as a program that connects K-12 schools and local farms and has the objectives of serving healthy meals in school cafeterias; improving student nutrition; providing agriculture, health and nutrition education; and supporting local and regional farmers.

Survey. A cover letter describing the purpose of the survey and a link to the questionnaire was emailed to representatives $(n=60)$ from all UCCE counties. The questionnaire was composed of 26 items that were either categorical "yes/no/I'm not sure" questions or open-ended questions allowing for further explanation. An additional item was provided at the end of the questionnaire for comments. Respondents were instructed to return the survey within 11 days. A follow-up email was sent to all participants after 7 days. This protocol resulted in a $28 \%$ ( $n$ $=17$ ) response rate, typical in a survey of this kind. Respondents represented 21 counties, with some representing more than one county; in addition, one was a representative from a campus-based unit of ANR. Questionnaire respondents included three county directors, six NFCS advisors, four 4-HYD advisors, one NFCS and 4-HYD advisor, and three other related UCCE academic personnel (an environmental horticulture advisor, a 4-H Healthy Living coordinator, and a strategic initiative leader). The responding counties were Riverside, San Mateo and San Francisco; San Bernardino, Stanislaus and Merced; Contra Costa, Yolo, Amador, Calaveras, El Dorado and Tuolumne; Mariposa, Butte, Tulare, Alameda, ShastaTrinity, Santa Clara, Ventura and Los Angeles. (Grouped counties are served by a single UCCE office.)

Farm to School and school gardens. All 21 counties responding to the survey reported that they had provided a leadership role in school gardens, after-school gardens and/or Farm to School programs during the previous 5 years (2006-2011). Five out of 17 respondents reported that their counties provided a leadership role in Farm to School programs. Fourteen out of 17 respondents indicated that they individually played a leadership role in school garden programs, including serving as a key collaborator on a project, organizing and coordinating community partners, acting as school/agriculture stakeholders and/or serving as a principal investigator, coprincipal investigator

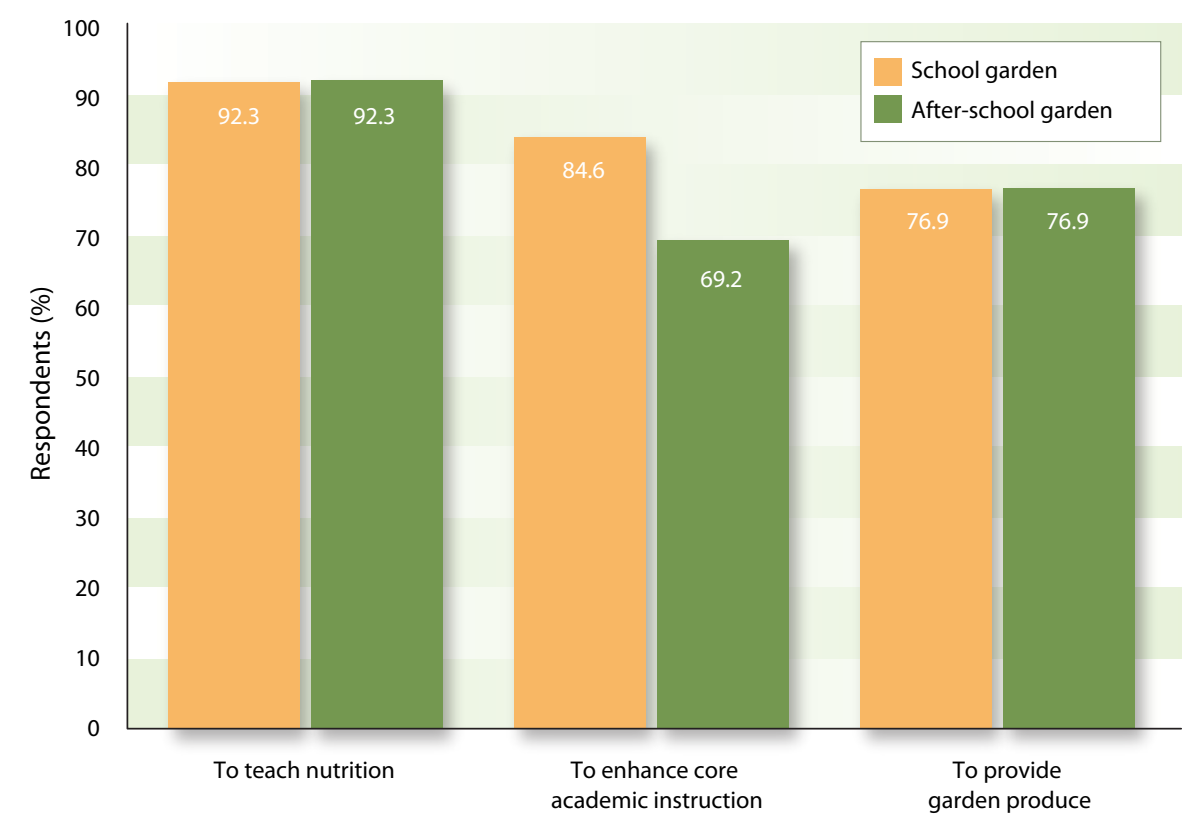

Fig. 1. Top three answers to a question on the purpose of school and after-school garden programs. Respondents ( $n=13$ ) first answered "yes" to the question: "Over the past 5 years, has your UCCE county program provided a leadership role in any pre-kindergarten to 12 th grade school garden programs?" 
or key collaborator on a research study. The most frequently reported reasons for having school and after-school gardens were to teach nutrition, enhance core academic instruction and provide garden produce (fig. 1). Additional reasons cited in the free responses included to study the psychological impacts of school gardens, enhance science and environmental education, teach composting, increase

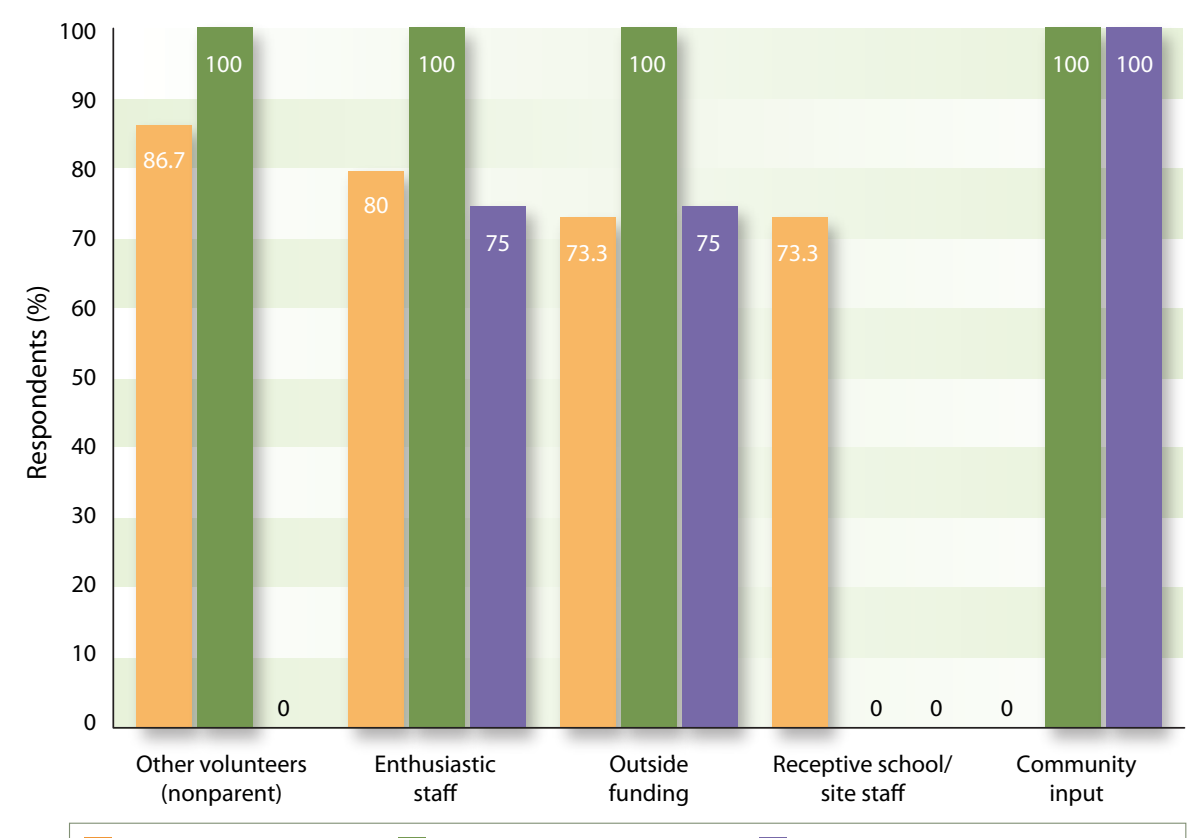

Successful school garden Successful after-school garden Successful Farm to School program

Fig. 2. Top answers to a question on the perceived factors contributing to successful school and after-school gardens and Farm to School programs. Respondents $(n=15)$ first answered "yes" to the question: "Over the past 5 years, has your UCCE county program provided a leadership role in any pre-kindergarten to 12th grade school garden programs?"

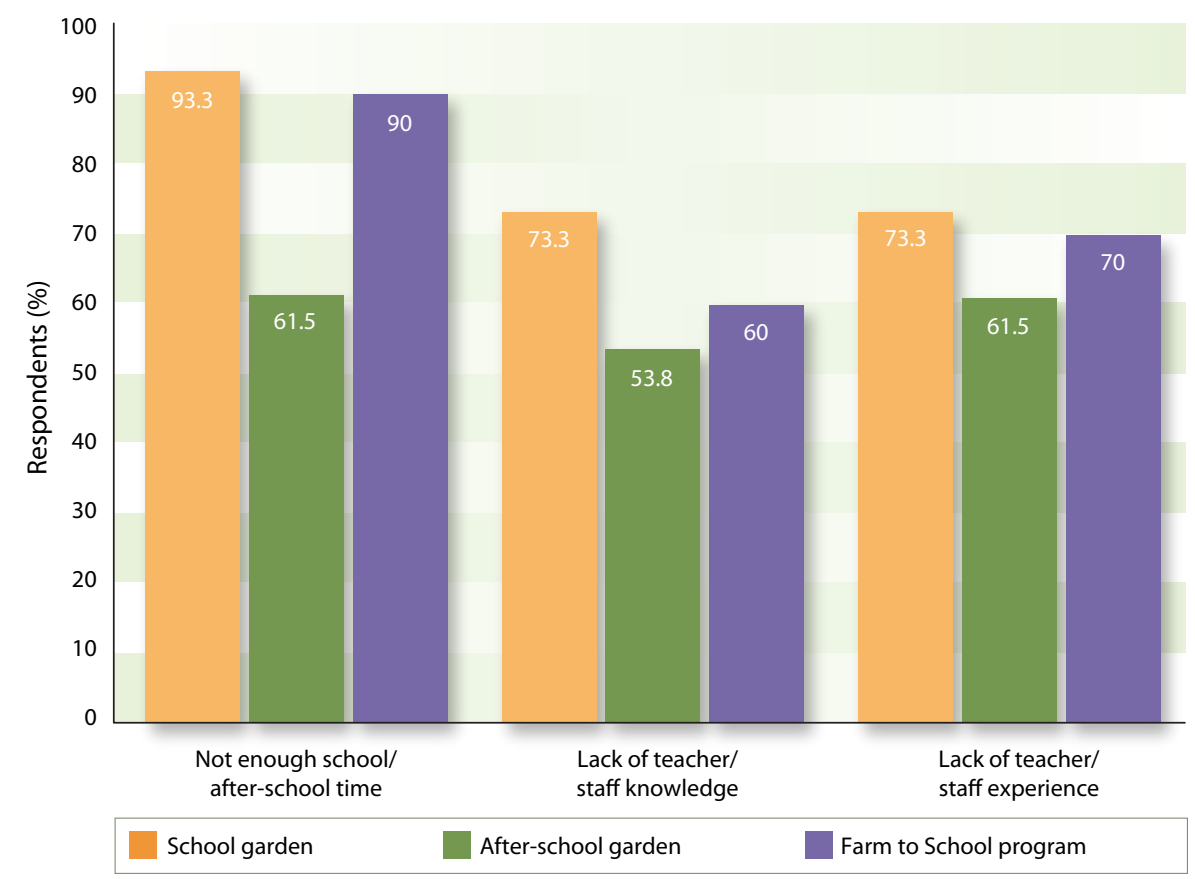

Fig. 3. Top three answers to a question on the perceived barriers to successful school and afterschool gardens and Farm to School programs. Respondents $(n=15)$ first answered "yes" to the question: "Over the past 5 years, has your UCCE county program provided a leadership role in any pre-kindergarten to 12th grade school garden programs?" agricultural literacy, teach food origins, participate in service learning (which integrates community service with instruction and reflection) and provide a Gardening Journalism Academy.

Reasons for success. The factors most frequently cited as contributing to successful school and after-school garden and Farm to School programs were community and nonparent volunteers, outside funding and enthusiastic staff (fig. 2). The 17 respondents indicated that the success of these programs was also aided by the multidisciplinary efforts within UC ANR (Master Gardeners, Expanded Food and Nutrition Education Program, UC CalFresh, 4-H Youth and Development advisors, farm advisors), Farm Bureau, Fair Board and 4-H Teens as Teachers.

Barriers. The most common factors cited as barriers to school and after-school gardens and Farm to School programs were lack of time and lack of knowledge and experience among teachers and staff (fig. 3). Additional barriers included lack of staff, cutbacks, competing programs for youth (sports) and lack of after-school garden-related educational materials for mixed-age groups. With regard to the Farm to School programs, one respondent perceived increased expense to schools, absence of tools to link local farmers with schools, a lack of growers and a lack of appropriate facilities in school kitchens.

UC ANR internal program coordination. Additional information gathered from the questionnaire included a more in-depth description of UC ANR's internal programs and activities. Thirteen of the 17 respondents indicated that their counties have an active Master Gardener Program, and 10 indicated that their master gardeners work with school or after-school garden programs or Farm to School programs. This internal program coordination was cited as an important factor for implementing successful school and after-school garden programs and Farm to School programs. These results suggest that the multidisciplinary and highly collaborative UC Cooperative Extension network has the potential to provide an important framework for successful school gardens, after-school gardens and Farm to School programs.

Highlights from UCCE-evaluated programs are provided below. 


\section{Contra Costa County}

A unique UCCE program in Contra Costa County brings many young schoolaged children, especially those in grades 1 and 2, to an edible garden at the county fairgrounds. The site is also home to an agriculture museum. Approximately 1,700 students, 67 teachers and many parents visited the site during the 2010-2011 school year. Process evaluation, which documents and evaluates the development of a program from its inception, has demonstrated positive attitudes toward the program among teachers, and results support the concept that teachers value the emphasis on local agriculture in the education process. However, these evaluations lack control groups of children who did not visit the edible garden, making it difficult to draw authoritative conclusions about the program's success.

\section{Contra Costa and Nevada counties}

UCCE Contra Costa and Nevada counties collaborated to initiate the UC Sustainable Community Project, a federally funded Children, Youth and Families at Risk (CYFAR) Sustainable Community Project that will begin participant enrollment in February 2012. A key element of the project is place-based learning, including at least one field trip to a farm. Both counties are partnering with master gardeners, and all intervention sites have gardens. The program will use the $4-\mathrm{H}$ Teens as Teachers model to deliver the majority of the education to the younger participants (in grades 2 to 5). The shortterm goals of the program include improvement in youth knowledge about nutrition, gardening, agriculture, cooking and health; improvement in the ability to act on this knowledge; and improvement in physical fitness. The program leaders expect to provide participants with the skills to grow and cook their own food to support their personal health goals.

As this is a nationally funded project, evaluation tools have already been developed, and a research team at Arizona State University will analyze pre- and post-intervention data. An exciting aspect of this project is that it supports the recent Institute of Medicine (of the National Academy of Sciences) call for innovative techniques, integrating gardening and Farm to School programs with new technologies. For example, teens will use iPad 2 applications to identify and map safe

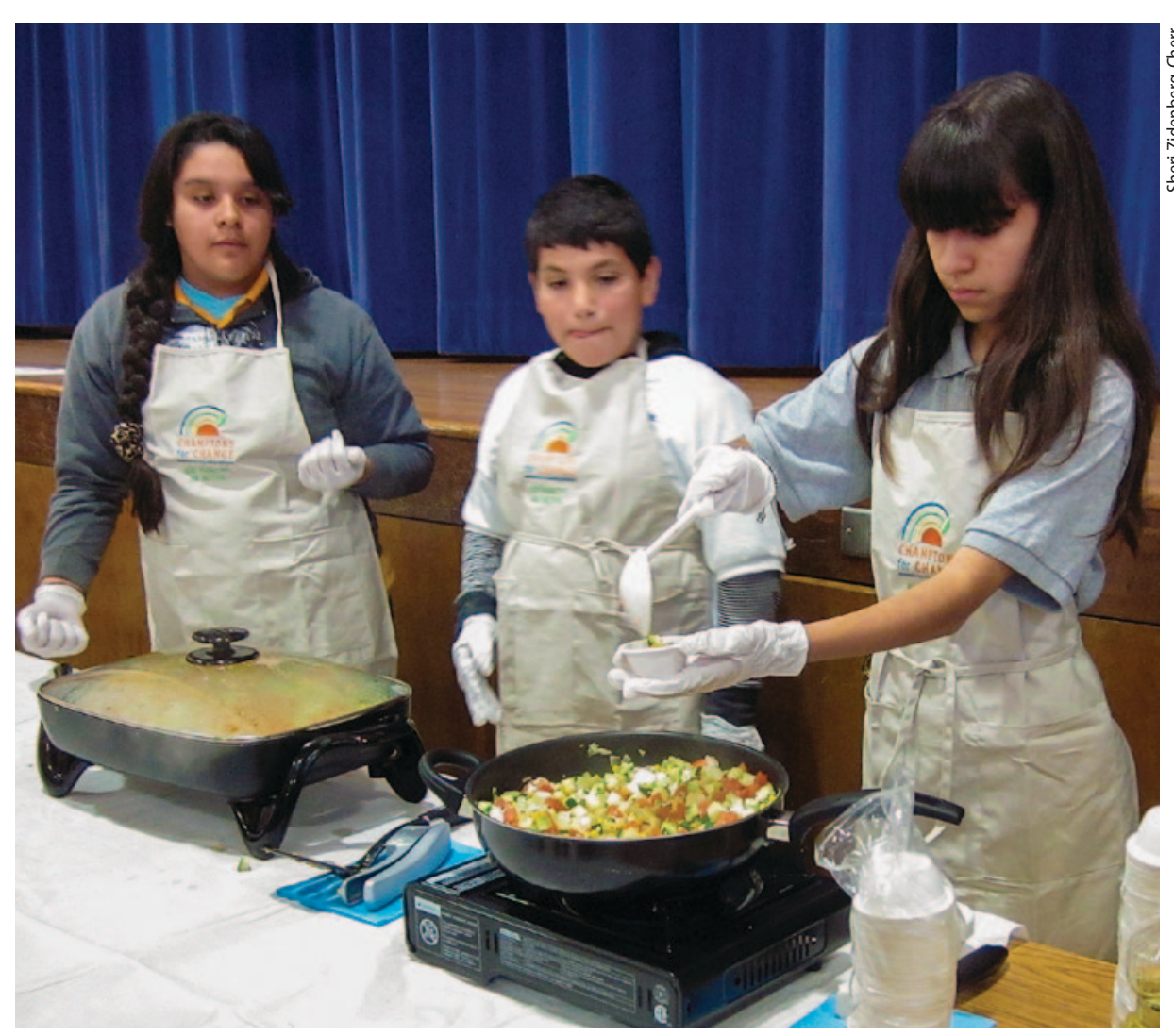

Nutrition and food education in schools has increased nationwide. Partnerships have formed among school nutrition directors, farmers, community organizations and parent volunteers. Above, students at Madison Middle School, Oakland, CA, prepare a vegetable medley for the Harvest of the Month tasting and nutrition demonstration.

routes to school and will share their findings by teaching children about walking and biking paths in their communities. Several education lessons will be delivered using accredited applications, and all data analysis will be collected with "clicker" technology, which uses wireless student response pads that allow instructors to instantly assess how well students understand the material presented.

\section{San Bernardino County}

In San Bernardino County, a team consisting of UCCE staff (a 4-H Youth Development advisor, an environmental horticulture advisor and county master gardeners) and academic personnel from the Fielding Graduate University Department of Psychology used a multidisciplinary approach to evaluate the impact of school gardens on nutrition knowledge and psychological parameters including attention and mood. Students in first- and second-grade classrooms were assessed pre- and post-intervention for nutrition knowledge using the Eating Healthy from Farm to Fork: Promoting School Wellness assessment tool. Teachers were trained to deliver this curriculum in its entirety and to use the 4- $\mathrm{H}$ gardening curriculum See Them Sprout. In addition, students spent 30 minutes in the garden each Friday.

At the end of the 14-week semester, the post-test results showed a statistically significant increase in fresh fruit and vegetable knowledge. A unique aspect of this project was the attention given to the psychological impact of the school garden. Children worked in the garden for only one semester, allowing investigators to use a cross-over design to compare gardening and nongardening children both within and between groups. Assessments of mood and attention were conducted before and after the 30-minute garden session and before and after the matched control nongardening activity sessions each Friday over two semesters. The following semester, this procedure was repeated with the group assignments reversed. Assessments of self-efficacy and well-being were conducted with individual students, using longer measures at the beginning and end of each semester. Results of this study are pending analysis. 
consumption and enjoyment of fruits and vegetables, (2) improve dietary patterns and increase physical activity consistent with the 2010 U.S. Dietary Guidelines for Americans, (3) improve science-processing skills to sustain patterns learned and adopted through participating in the program, (4) promote positive changes in the school environment to support dietary and exercise patterns and student health and (5) facilitate the development of an infrastructure to sustain the program beyond the funding period. To document student outcomes and environmental changes resulting from this multicomponent, multidisciplinary approach to obesity prevention, a randomized, controlled, double-blind intervention will be implemented for one academic year through collaboration among faculty and staff from UC Davis, UC ANR, the Agricultural Sustainability Institute at UC Davis and the UC Davis Betty Irene Moore School of Nursing.

The factors contributing to obesity are numerous and interrelated. Meeting the complex challenges of obesity prevention will require extensive and diverse collaboration with shared responsibility and common goals. The study will explore and document the effectiveness of an interdisciplinary team in developing comprehensive nutrition and lifestyle education programs that can be delivered throughout the state. In the future, these teams will include UC faculty; UCCE nutrition and youth development specialists and advisors, and Agricultural Sustainability Institute staff; food and agriculture industry representatives; public school educators, administrators, afterschool providers and families; community members; health practitioners; farmers; and state/county agency nutrition, food science, agriculture and health-care representatives - all developing coordinated programs that can be delivered throughout the state.

\section{R.E. Scherr is Postdoctoral Scholar, Department} of Nutrition; R.J. Cox is Graduate Student, Department of Nutrition; G. Feenstra is Academic Coordinator, Food and Society, Sustainable Agriculture Research and Education Program, Agricultural Sustainability Institute; and S. Zidenberg-Cherr is Nutrition Science Specialist/ AES Scientist, Department of Nutrition; all at UC Davis.

\section{References}

Action for Healthy Kids. 2008. Progress or Promises? What's Working for and against Healthy Schools. www. actionforhealthykids.org/resources/files/progressorprom ises.pdf.

Allen P, Guthman J. 2006. From "Old School" to "Farm to School": Neoliberalization from the ground up. Agr Hu man Values 23:401-15.

Briggs M, Mueller CG, Fleischhacker S. 2010. Position of the American Dietetic Association, School Nutrition Association, and Society for Nutrition Education: Comprehensive school nutrition services. J Am Diet Assoc 110(11):1738-49.

California Economy. 2011. www.netstate.com/economy/ ca_economy.htm.

[CAPOP] Committee on Accelerating Progress in Obesity Prevention. 2012. Accelerating Progress in Obesity Prevention: Solving the Weight of the Nation. Institute of Medicine. Washington, DC. www.iom.edu/ /media/Files/ Report\%20Files/2012/APOP/APOP_rb.pdf.

[CDC] Centers for Disease Control and Prevention. 1996. Guidelines for school health programs to promote lifelong healthy eating. MMWR Recomm Rep 45(RR-9):1-41.

CDC. 2003. Physical activity and good nutrition: Essentia elements to prevent chronic diseases and obesity 2003. Nutr Clin Care 6(3):135-8.

[CPPCO] Committee on Progress in Preventing Childhood Obesity. 2007. Progress in Preventing Childhood Obesity: How Do We Measure Up? Institute of Medicine. Washington, DC. www.iom.edu/ /media/Files/Report\%20Files/2006/Progress-in-Preventing-Childhood Obesity--How-Do-We-Measure-Up/11722_reportbrief pdf.

Economos CD, Hyatt RR, Goldberg JP, et al. 2007. A community intervention reduces $\mathrm{BMI} z$-score in children:

Shape Up Somerville first year results. Obesity 15(5):1325 $-36$.

Feenstra G, Ohmart J. 2004. A Report by UC Sustainable Agriculture Research \& Education Program. Yolo County Farm to School Evaluation Report for the California Farm to School Program. Davis, CA.

Feenstra G, Ohmart J. 2005. A Report of UC Sustainable Agriculture Research \& Education Program. Yolo County Farm to School Evaluation Report. Davis CA.
Feenstra G, Ohmart J. 2012. The evolution of farm to school programs in the United States: Connecting childhood health, farms and communities. Childhood Obesity 8(4): 283-92.

Graham H, Beall DL, Lussier M, et al. 2005. Use of school gardens in academic instruction. J Nutr Educ Behav 37(3):147-51

Gubbels JS, Kremers SP, Stafleu A, et al. 2011. Association between parenting practices and children's dietary intake, activity behavior and development of body mass index: The KOALA Birth Cohort Study. Int J Behav Nutr Phys Act 8:18.

Hayden-Smith R. 2006. Soldiers of the Soil: A Historical Review of the United States School Garden Army. 4-H Center for Youth Development Monograph Series. UC Davis.

Hazzard EL, Moreno E, Beall DL, Zidenberg-Cherr S. 2011. Best practices models for implementing, sustaining and utilizing instructional school gardens in California. J Nutr Educ Behav 43(5):409-13.

Hazzard EL, Moreno E, Beall DL, Zidenberg-Cherr S. 2012 An evaluation of the California Instructional School Garden Program. Public Health Nutr 15(2):285-90.

Joshi A, Azuma AM. 2009. Bearing Fruit: Farm to School Program Evaluation Resources and Recommendations. Occidental College.

Joshi A, Azuma AM, Feenstra GW. 2008. Do farm-toschool programs make a difference? Findings and future research needs. J Hunger Environ Nutr 3(2):229-46.

Kane D, Hayden-Smith R. 2008. What's for Lunch? A Review of School Food and Garden-based Education in the United States Using the Portland Public Schools as a Model for Change. EcoTrust.

Kohlstedt SG. 2008. "A better crop of boys and girls": The school gardening movement, 1890-1920. Hist Educ Quart 48(1):58-93.

McAleese JD, Rankin LL. 2007. Garden-based nutrition education affects fruit and vegetable consumption in sixth-grade adolescents. J Am Diet Assoc 107(4):662-5

Morris JL, Neustadter A, Zidenberg-Cherr S. 2001. Firstgrade gardeners more likely to taste vegetables. Calif Agr 55(1):43-6
Morris JL, Zidenberg-Cherr S. 2002. Garden-enhanced nutrition curriculum improves fourth-grade school children's knowledge of nutrition and preferences for some vegetables. J Am Diet Assoc 102(1):91-3.

National Farm to School Network. 2012. www.farmtoschool.org/policies.php

Ogden CL, Carroll MD, Curtin LR, et al. 2010. Prevalence of high body mass index in U.S. children and adolescents, 2007-2008. JAMA 303(3):242-9.

Ozer EJ. 2007. The effects of school gardens on students and schools: Conceptualization and considerations for maximizing healthy development. Health Educ Behav 34(6):846-63.

Ratliffe MM, Merrigan KA, Rogers BL, Goldberg JP. 2011 The effects of school garden experiences on middle school-aged students' knowledge, attitudes, and behaviors associated with vegetable consumption. Health Promot Pract 12(1):36-43.

Robinson-O'Brien R, Story M, Heim S. 2009. Impact of garden-based youth nutrition intervention programs: A review. J Am Diet Assoc 109(2)273-80.

Story M, Kaphingst KM, Robinson-O'Brien R, Glanz K. 2008. Creating healthy food and eating environments: Policy and environmental approaches. Ann Rev Public Health 29:253-72.

Subramaniam A. 2002. Garden-Based Learning in Basic Education: A Historical Review. www.ca4h.org/files/1229. pdf.

[US DHHS] US Department of Health and Human Services. 2010. HHS Secretary and Surgeon General Join First Lady to Announce Plans to Combat Overweight and Obesity and Support Healthy Choices. www.hhs.gov/ news/press/2010pres/01/20100128c.html.

[WHTF] White House Task Force on Childhood Obesity. 2010. Report to the President: Solving the Problem of Childhood Obesity Within a Generation. Washington, DC www.letsmove.gov/white-house-task-force-childhoodobesity-report-president 